\title{
EDITORIAL
}

\section{HUMBLE SERVANTS TO HUMAN SOCIETY}

\author{
M. Boyanov' ${ }^{1}$ M. Boyanova² \\ ${ }^{1}$ Clinic of Endocrinology and Metabolism, University Hospital Alexandrovska, \\ Department Internal Medicine, Medical University - Sofia, Bulgaria \\ 2Unit of Endocrinology, Clinic of Endocrinology and Nephrology, "Acibadem City Clinic Tokuda Hospital" - \\ Sofia, Bulgaria
}

\section{Key points}

The current epidemic due to COVID-19 has made many physicians re-think their role as servants to human society. As physicians, practicing clinical endocrinology in an East-European country, we would like to share some simple observations which were made even more obvious by the current medical crisis:

1. Medicine is a double edged sword - it is both a social and financial practice and not simply a medicine oriented business. The authorities should realize that investing money in medical activities cannot always have a foreseeable and measurable economic effect. In fact many governments seem to view medicine as an unnecessary expense and a drain to the economy - this in itself is a gross misconduct of their purpose which should be geared towards the value of their citizens' lives and not the country's constant economic growth.

2. Medical staff needs high morale to perform their duties, especially in a highly hazardous situation. The Hippocrates' vow must be revised and upgraded to suit this more modern time.

3. Our knowledge of nature and the natural forces at work is still limited. We must accept this fact of life and consequently have to find some method or philosophy to alleviate the feeling of helplessness brought on from this knowledge. We are not yet the total masters of the world we think ourselves to be, and to think otherwise would be hazardous on our part.
4. Humans across the world may vary in their genetics, phenotypes and responses to external stimuli as the human organism is very multifactorial. This can explain the observed differences between countries all over the world in response to the same external factor (in this case COVID-19).

5. Preserving our health means that we should be ready to give up some personal rights and liberties.

In conclusion, a great crisis like the COVID-19 one is a time for reevaluation of the past and elaboration of new strategies. We, medical personnel from across the world, must be united in the struggle against disease and death.

This is a personal perspective of the COVID-19 crisis. The viewpoint reflects the thoughts of two clinical endocrinologists, who are married and have a child. So, they share their thoughts as dedicated physicians and as human beings who want to protect their families [1].

1. Medicine is a double edged sword - it is both a social and financial practice and not simply a medicine oriented business. The authorities should realize that investing money in medical activities cannot always have a foreseeable and measurable economic effect. In fact many governments seem to view medicine as an unnecessary expense and a drain to the economy - this in itself is a gross misconduct of their purpose which should be geared towards the value of their citizens' lives and not the country's constant economic growth. 
Everybody is wondering: „Where have all the other patients gone?" The emergency departments all over the world, including Bulgaria, are empty. The hospitals are admitting only a small proportion of patients with acute illnesses. The physicians' offices are desert. But the overall mortality rate has not increased in the country. So we ask ourselves, did all these chronically ill patients really need the care that we provided and do they really benefit from it? Are all those clinical trials of new medications really proving benefit and how do we define it? Or is it a matter of chance? Maybe medicine has met too many needs of one society of consumers and have provided more and more to the richest part of the human race, ignoring the needs of the poor and the hungry part of the society. The latter is particularly vulnerable to "the hidden threats" around us, as poor health and poor economic status means less access to healthcare and more poorly controlled chronic conditions, which have been proposed as risk factors for COVID-19 infection, together with older age [2]. Nobody expected that humanity would be the key to fighting a pandemic. Nobody expected that flattening the curve would mean taking from the richest what they wish to give away and from the poor everything that they have left. Actually, the future of the human race has always been in the hands of a handful of proud people, rich inside and in many cases poor outside. In our society of consumers, medicine is not what it was meant to be and now is the time to "wake up" both as professionals and as human beings.

2. Medical staff still needs high morale to perform all their duties especially in a highly hazardous milieu. The Hippocrates' vow must be revised and upgraded to suit modern times.

There is nothing like the profession of a "physician". It is a moral duty to help the one who needs help. However, people are not very thankful in recent years. In fact, they act as they are in the bank or in the shop - ordering and demanding. Now they demand to live. Physicians, on the other hand, demand to work with PPE. Nothing more can be added.

3. Our knowledge about nature and natural forces is still limited. We have to simply live with that idea. We must accept this fact of life and consequently have to find some method or philosophy to alleviate the feeling of helplessness brought on from this knowledge. We are not yet the total masters of the world we think ourselves to be, and to think otherwise would be hazardous on our part.

We live an easy life, full of joy and comfort. We have not faced wars or natural disasters, recently. Therefore, people started thinking they are immortal. They forgot to appreciate life, their relatives and the opportunity to make personal choices freely and responsibly. In Bulgaria, there was a trend in the society to disrespect physicians. Still, for some of these same people, even being in the middle of a historical event is not a reason to re-evaluate their behavior toward healthcare providers and vision of life.

4. Humans across the world may vary in their genetics, phenotypes and answers to external stimuli. The human organism is very multifactorial; it is a very rich entity. This can explain the observed differences between countries all over the world in response to the same external factor (in this case COVID-19).

For example, on the contrary to what was assumed in a recent publication [3], the effect of ACE-inhibitors and angiotensin-receptor blockers cannot be evaluated and justified based on studies from China, because the genetics of people in China differ from genetics of people in Europe. For example, thyroidassociated ophthalmopathy has different clinical presentation compared to its presentation among Caucasians and complications differ as well. Genetic predisposition is not to be overlooked, even when we are facing a pandemic.

5. Preserving our health means that we should be ready to give up some personal rights and liberties. Too much rights and frivolous freedoms render people undisciplined and unprepared - some even downright resistant due to 'perceived' over exaggerations regarding this disease. This only facilitates the societal inability to deal with such situations and further exasperating the problems we face in the rapid spread of COVID-19, leaving us all vulnerable to it and other infectious diseases that may appear in the future.

Social distancing seems to work. However, the prognosis is that it would take longer than expected to fight the pandemic. Living in a completely new way could be a hardship and nobody can estimate or give a prognosis of the consequences.

In conclusion, a great crisis like COVID-19 should be the impetus for the reevaluation of the past and discussions of new strategies in combating global pandemics. We, the medical personnel across the world, must be united in the struggle against disease and death with global strategies needed in this never ending combat with nature itself.

\section{REFERENCES:}

1. Christian R. Am I Part of the Cure or Am I Part of the Disease? Keeping Coronavirus Out When a Doctor Comes Home. N Engl J Med, March 18, 2020;DOI: 10.1056/NEJMp2004768;

2. Wang D, Hu B, Hu C, et al. Clinical Characteristics of 138 Hospitalized Patients With 2019 Novel Coronavirus-Infected Pneumonia in Wuhan, China. JAMA. 2020;323(11):10611069. doi:10.1001/jama.2020.1585

3. Vaduganathan M et al. Renin-Angiotensin-Aldosterone System Inhibitors in Patients with Covid-19. N Engl J Med. March 30, 2020, DOI: 10.1056/NEJMsr2005760. 